\title{
Artificial Neural Network Approach for Modeling of Soil Temperature: A Case Study for Bathalagoda Area
}

\author{
N.A.D. N. Napagoda ${ }^{1}$ and C.D.Tilakaratne ${ }^{2}$ \\ ${ }^{1}$ Department of Mathematical Sciences, Faculty of Applied Sciences \\ Wayamba University of Sri Lanka, Kuliyapitiya \\ ${ }^{2}$ Department of Statistics, University of Colombo, Colombo
}

\begin{abstract}
Soil temperature is an important meteorological parameter that affects various physical and chemical reactions in the soil. However, measuring soil temperature is very expensive. Therefore, an attempt to model soil temperature using available agro-climatic variables is very useful. This study aims at finding a better approach for forecasting morning and evening soil temperature at depths $5 \mathrm{~cm}$ and $10 \mathrm{~cm}$ with the minimum usage of historical soil temperature data. Weekly data collected at Bathalagoda Rice Research and Development Institute for 20 years were used in this study. Commonly used statistical models such as probabilistic and Markov chain models have limitation as they require historical soil temperature in order to obtain forecasts. Hence, Nonlinear Auto Regressive neural network with exogenous input (NARX) models and Feedforward Neural Network (FNN) models were employed to obtain targeted forecasts. Potential input variables for network models were selected based on serial cross correlation and autocorrelation analysis. Models with different combinations of input variables were tested and the best sets of input variables were selected based on the prediction accuracy. The Mean Square Error (MSE) and the coefficient of determination $\left(R^{2}\right)$ of the model of predicted values on actual values of test cases were employed to compare the performances of various neural networks. Suitable models with relatively simple structures were selected and their robustness was analyzed. NARX models showed lower MSE values and higher $R^{2}$ values than FNN models, suggesting that they could be used as more reliable and suitable models to predict weekly mean soil temperatures at depths $5 \mathrm{~cm}$ and $10 \mathrm{~cm}$ in Bathalagoda area.
\end{abstract}

Keywords: Climate Variable, Feedforward Neural Network, Forecasting models, Nonlinear Auto Regressive neural network with exogenous inputs.

\section{Introduction}

Prediction of weather parameters such as soil temperature, air temperature, wind speed, relative humidity and rainfall have been shown to be useful for 
agricultural purposes. These weather parameters have also been found to be highly correlated to solar energy (George, 2001). Among these parameters, soil temperature is one of the most important factor that affects agricultural processes. However, obtaining accurate measurements of soil temperature are very expensive. Therefore, the development of predictive models to predict soil temperature without using historical soil temperature data is essential. However, it is a challenging task.

Soil temperature is an important meteorological parameter, especially for ground source heat pump applications, solar energy applications such as the passive heating and cooling of buildings, frost prediction and other agricultural applications (Mihalakakou, 2002). It plays an important role in adjusting and controlling the interactive processes between the ground and the atmosphere. Soil temperature determines the type and rate of different physical and chemical reactions in the soil. It also affects diffusion of nutrients in soil and their uptake by plants. Furthermore, it has been shown that determination of ground surface temperature and ground temperature at different depths is very important for agricultural industries (Y1lmaz, 2009). However, prediction of soil temperature is rather difficult, especially near the ground surface where the soil temperature variations are the highest (Mihalakakou, 2002).

In recent years, there have been several studies concerning the determination of soil temperatures using traditional statistical models, other mathematical models and experimental methods (Tenge et al., 1998; Enrique et al., 1999; Kang et al., 2000; George, 2001; Mihalakakou, 2002; Koçaket al., 2006; Gao et al., 2007; 2008; Droulia et al., 2009; Prangnell and McGowan, 2009). In addition, models based Artificial Neural Networks (ANN) have also been developed. Traditional statistical models have limitations as forecasting models for soil temperature since they require historical soil temperature data for forecasting and it is very expensive to measure soil temperature. On the other hand, ANNs have been used in several studies to estimate meteorological variables.

Soil temperature and other agro-climatic variables involved may have complex inter-relationships. Such problems can be efficiently solved using ANNs. ANN have been found to provide better solutions than traditional statistical methods when applied to poorly defined and poorly understood complex systems. Various ANN models such as, Radial Basis Neural Networks and Feedforward Neural Networks (FNN) have been employed to model various meteorological variables (Chun-Chieh et al., 1997; Felker \& Han, 1997; Mehmet, 2010). In past studies (for instance, George, 2001; Mihalakakou, 2002) the potential of ANNs as alternatives to traditional statistical models for predicting soil temperature was evaluated. ANN models adopt approaches that can handle non linear and complex data and these approaches can be used without prior assumptions about the data. Due to difficulties and high costs associated with direct measurements of soil temperatures, ANN models provide an alternative to traditional statistical models for forecasting soil temperature. 
Among the many structures of ANN that have been studied, the most widely used network structures for soil temperatures are the FNN models. Although FNNs have been employed to forecast soil temperature models in literature, they have all used past soil temperature data along with other environmental and physical factors such as, soil moisture, soil surface temperature etc as input variables. In contrast to the other studies, Yang et. al (1997) developed a FNN model to simulate the soil temperature at different depths (100, 500 and 1500 $\mathrm{mm}$ ) by considering readily available meteorological parameters. As input variables, they used a few meteorological variables which measured at a weather station at central experimental farm in Canada, for five years. The model input variables consisted of daily rainfall, evaporation and the day of the year. Hayati and Mohebi (2008) explored the application of FNNs to study the design of short-term temperature forecasting (STTF) systems in Iran. However, none of the methods found in literature have focused on forecasting soil temperature using a large number of other agro-climatic variables.

Nonlinear Auto Regressive neural network with exogenous input model (NARX) was rarely employed in past studies to forecast soil temperature. However, NARX has the ability to build non linear autoregressive model and hence it is suitable to identify non linear dependencies among soil temperature and other climatic variables. Shahlla et.al (2011) developed ANN models to estimate soil temperature for any day by using historical data related to various meteorological variables between the years of 1980 and 1984 in Iraq. Soil temperature at depths of 5, 10, 20, 50 and $100 \mathrm{~cm}$ within the time 9, 12 and 15 hours were used. They have constructed three ANN models: (1) FNN trained with a Back propagation algorithm (BP) (2) FNN trained with Cascade-Forward algorithm, and, (3) NARX. Their results indicated that NARX model, consisting of five input variables: previous day's minimum and maximum atmospheric temperature, sunshine hours, time and day of the year, was the best model for forecasting the soil temperature for targeted depths of the city of Nineveh in Iraq.

The main objective of our study is to propose a better approach to forecast morning and evening soil temperature at depths $5 \mathrm{~cm}$ and $10 \mathrm{~cm}$, at Bathalagoda area. Our attempt was to develop models to forecast soil temperature with the minimum use past soil temperature data, because obtaining such measures is very expensive. Therefore, we attempted to develop forecasting models mainly based on other agro-climatic variables. Following the past studies (for instance, Yang et. al., 1997; Mehmet, 2010; Amani et.al., 2011; Shahlla et.al., 2011), we adopted suitable ANN models for this purpose.

This study may be the first study in Sri Lankan context that applies an ANN approach to build forecasting models for soil temperature. Furthermore, it differs from Shahlla et.al (2011) in the sense that the selection of potential input variables in this study is based on statistical techniques rather than selecting them arbitrarily. Moreover, we paid attention to the variation of soil temperature 
during a day and hence considered morning and evening soil temperature separately rather than considering an average value.

The rest of this paper is organized as follows: first the theoretical background of the ANN models and different network parameters are explained. Then a subsequent section describes the experiments carried out. This section is followed by results and discussion. The conclusions are drawn up in the final section.

\section{Methods and Experiments}

Traditional statistical techniques, such as time series and Markov chain models, are inappropriate for building forecasting models in this case, as the aim of this study is to propose a model which has ability to forecast soil temperature with the minimum use of its historical data. Multiple regressions models also have limitations due to presence of autocorrelations of observation of the response variables used in this study. Therefore, as with the past studies, this study also adopted two ANN models, namely FNN and NARX as forecasting models. The techniques behind these two modeling approaches are briefly discussed in this section. The experiments carried out to achieve the objective are also presented at the later part.

\subsection{Feedforward Neural Network (FNN) model}

In a FNN each neuron in a layer is connected to all the neurons of the next layer and the neurons in one layer are not connected among themselves. All the nodes within a layer act simultaneously. The data passing through the connections from one neuron to another are multiplied by weights that control the strength of a passing signal. When these weights are modified, the data transferred through the network changes consequently, the network output also changes. The signal emanating from the output node is the network's solution to the input problem. An example of FNN model is shown in Figure 01.

Each neuron multiplies every input by its interconnection weight, sums the product and then passes the sum through a transfer function to produce its result.

The following equation gives the net input to the $j^{\text {th }}$ neuron of the current hidden layer,

$$
n e t_{j}=\sum_{i} w_{i j} l_{i}+b_{j}
$$

where $l_{i}$ is the output of the $i^{\text {th }}$ neuron of the input layer or the previous hidden layer, $w_{i j}$ is the weight of the link connecting $i^{\text {th }}$ neuron of the previous layer to 
$j^{\text {th }}$ neuron of the current hidden layer, and $b_{j}$ is the bias associated with the $j^{\text {th }}$ neuron of the current hidden layer.

The output of the $j^{\text {th }}$ neuron of the current hidden layer is given by,

$$
\text { out }_{j}=f\left(\text { net }_{j}\right)
$$

where $f$ is the transfer function associated with the hidden layer neurons. The Logistic-sigmoid function, which is usually a nonlinear function, was used in this study. Logistic-sigmoid is the most commonly used activation function in feedforward neural networks.

$$
f(x)=\frac{1}{1+e^{-x}}
$$

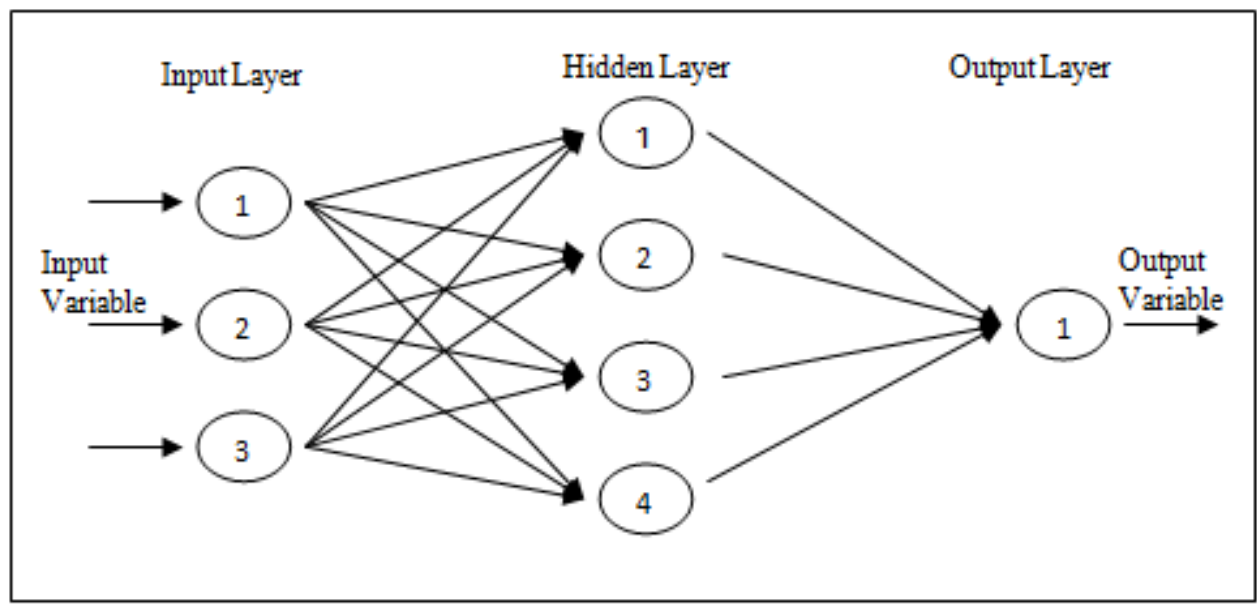

Figure 01: Architecture of a FNN

The input to and the output of the $k^{\text {th }}$ neuron in the output layer can be defined similarly. Equations (3) and (4) give the input to and the output of the $k^{\text {th }}$ neuron of the output layer respectively.

$$
n e t_{k}=\sum_{j} w_{j k} l_{j}+b_{k}
$$

where $l_{\mathrm{j}}$ is the output of the $j^{\text {th }}$ neuron of the previous hidden layer, $w_{\mathrm{jk}}$ is the weight of the link connecting $j^{\text {h }}$ neuron of the previous layer to $k^{\text {th }}$ neuron of the output layer, and $b_{k}$ is the bias associated with the $k^{\text {th }}$ neuron of the output layer.

$$
\text { out }_{k}=f^{\prime}\left(\text { net }_{k}\right)
$$


where $f^{\prime}$ is the transfer function associated with the output layer neurons. Usually, $f^{\prime}(x)=x$ is sufficient. The 'purelin' function represents the data in a broader range, which may have positive effect in the performance of the network.

An input vector is presented to the input layer, and then the network computes the output for the non-input units (Tilakaratne, 2004).

$$
\text { out }_{k}=f^{\prime}\left(\sum_{j} w_{j k} f\left(\sum_{i} w_{i j} l_{i}+b_{j}\right)+b_{k}\right)
$$

\subsection{Nonlinear Auto Regressive neural network with exogenous inputs (NARX) model}

The nonlinear autoregressive neural network with exogenous inputs (NARX) is a recurrent dynamic network, with feedback connections enclosing several layers of the network. The NARX model is based on the linear autoregressive neural network with exogenous inputs (ARX) model, which is commonly used in time-series modeling (Maria et. al., 2006). The defining equation for the NARX model is (Amani et.al., 2011; Shahlla et.al., 2011)

$$
y(n)=f\left[\left(y(n-1) ; u_{1}(n-1), u_{2}(n-1), \ldots, u_{n}(n-1)\right]\right.
$$

The output of an NARX model, $y(n)$, is related to a finite number of past outputs and exogenous inputs $\left(u_{i}(n-1): i=1 . . . n-1\right)$ as shown in (5). In this equation, $u_{i}(n-1)$ represents value of the $i^{\text {th }}$ exogenous input variable at time $n-1, y(n)$ is the output of the network which represents the value of the endogenous variable at time $n$, and $f$ is a nonlinear function. The NARX model can be implemented by using a FNN to approximate the function, $f$, where the next value of the dependent output variable, that is, $y(n)$ is regressed on current values of the output variable as well as the current values of exogenous input variables. A diagram of the resulting network is shown in Figure 02.

The output of a NARX network is an estimation based on a nonlinear dynamic system that fits the given model. The output is fed back as input to the feedforward neural network according to the standard NARX architecture. The main advantage of this architecture is that at the beginning of training only the actual values of $y(n-1)$ is needed to forecast $y(n)$. Therefore, minimum historical values are used as input variables to forecast future values of $y$.

There are many applications for the NARX network. It can be used as a predictor, to predict the next value of the input variable. It can also be used for nonlinear filtering, in which the target output is a noise-free version of the input variables. 


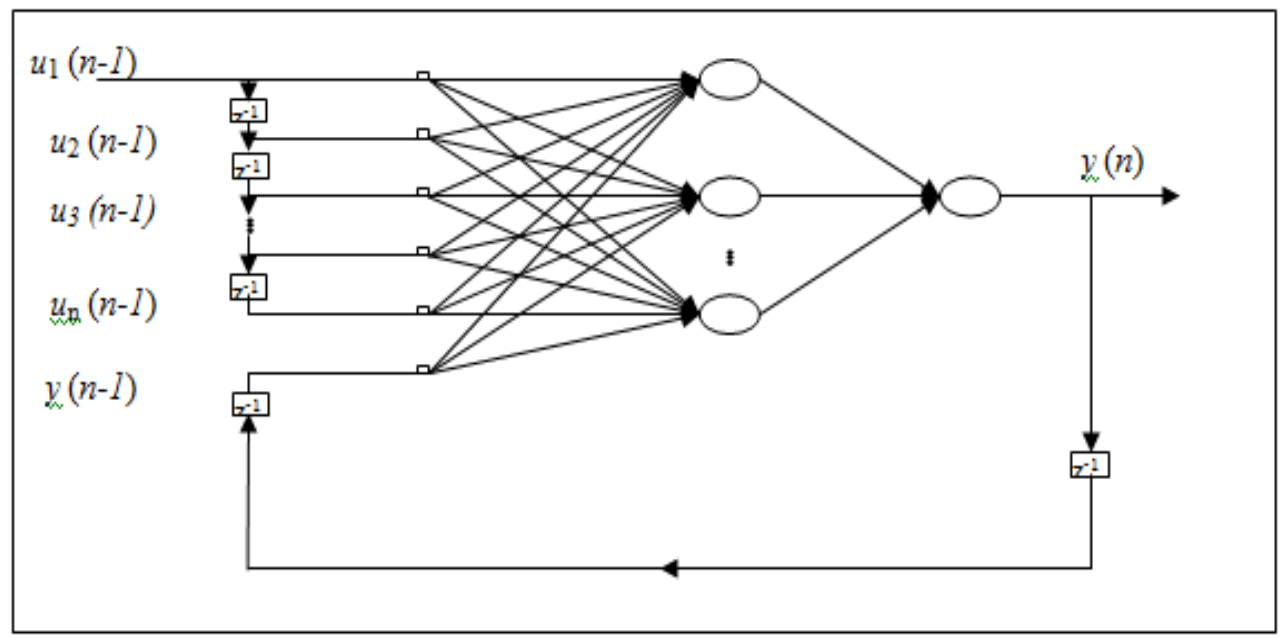

Figure 02: Architecture of a NARX

\subsection{Experiments}

The weekly agro-climatic data (weekly average minimum air temperature, weekly average maximum air temperature, weekly aggregate rainfall, weekly average sun shine hours, weekly average relative humidity (morning and evening), weekly average pan evaporation , weekly average wind velocity) from 1990 to 2010 provided by the Rice Research and Development Institutes (RRDI) located in Bathalagoda, were used for this study. Weekly average morning and evening soil temperature data at depths of $5 \mathrm{~cm}, 10 \mathrm{~cm}$ measured during the same period were also used. The aim was to identify four models to forecast morning and evening temperature at two depths concerned.

The data set was separated into training set, validation set and test sets. The most recent data (from 2009-10) consisting of 9\% of total data (93 observations) was included in the test set. Data from 2006-08 periods, amounting to $14 \%$ of total data (156 observations) was selected for the validation set. The rest of data (832 observations) was used as the training set.

Input variables were added according to the strength of cross-correlations between the response variable and the predicted variables. First, crosscorrelations between input and output variables and autocorrelations for each response variable at different lags were calculated to determine the potential input variables. Next, all possible input variable combinations were evaluated and the most suitable set of input variables were selected based on the performance of the neural network models.

After experimenting with several combinations of transfer functions, it was identified log sigmoid and linear functions are the best choice for the transfer 
functions between input - hidden layers and hidden-output layers, respectively. Several single hidden layer architectures were implemented, where the numbers of neurons in the hidden layer were varied. The artificial neural networks used in this analysis were fully connected, feedforward networks with a single input layer consisting of two to eight input neurons, a single hidden layer with three to ten hidden neurons and a single output layer with one output neuron. In addition, the input and hidden layer had a bias neuron feeding a continuously 'on' signal to each neuron in the layer. These networks were trained with the LevenbergMarquardt algorithm (Haykin, 1999). This algorithm appears to be the fastest method for training moderate-sized feedforward neural networks (Demuth et.al., 2006). Apart from this, it is well known as a robust algorithm.

Learning parameters such as learning rate and momentum can be more effective if they can be changed dynamically during the course of training. The value of the learning rate $(\alpha)$ has a great impact on the success of ANN applications (Haykin, 1999). If it is increased too much, learning becomes unstable and the neural network could oscillate back and forth across the error minimum or could wander aimlessly around the error landscape. If the learning rate is too small, then the search process for the minimum error will be slow, leading to long computation times.

The addition of a momentum term to the training law generally results in faster training. The weight changes continue in the direction it was heading with the introduction of a momentum term. This weight change would be a constant multiple of the previous weight change in the absence of an error. The momentum term makes the weight updating process faster making convergence faster. The whole training process has also been found to be more stable with the introduction of a momentum term (Haykin, 1999). The equation for momentum $(\Delta w(n))$ is given below:

$$
\Delta \omega(n)=\alpha \delta^{j}(n) x(n)+\lambda \Delta \omega(n-1)
$$

where $\Delta w(n)$ is the $n^{\text {th }}$ change in weight $w$ and the momentum term $\lambda \Delta w(n-1)$ is the momentum constant $\lambda$ multiplied by the previous weight change. The momentum constant $\lambda$ must be greater than zero and, to ensure convergence, should also be less than 1 . It is possible to express $\Delta w(n)$ as a sum of gradient estimates evaluated at the current and previous training steps by expressing this relationship recursively (Haykin, 1999).

Number of layers, and nodes in each layer of the NARX network as same as those of the FNN. Additionally, it was trained with the same training algorithm used to train the FNN network. When training NARX network, the input vector needs the actual average soil temperature only at the beginning of the period, while for later weeks it uses the respective predicted value as an input soil temperature. In this sense, although NARX requires previous week's average soil temperature data, the use of historical data is a minimum. 
Predicted values of the morning and evening soil temperature at different depths were compared with respective actual values by means of Mean Square Error (MSE) and the coefficient of determination $\left(\mathrm{R}^{2}\right)$ of the model of predicted values on actual values. Several training sessions were carried out to obtain the suitable number of nodes in the hidden layer and other parameters of FNN and NARX. The best combination of input variables was selected on basis of the smallest MSE and highest $\mathrm{R}^{2}$.

Four FNN models and four NARX models were identified as the better models to forecast morning and evening soil temperature at two depths.

\section{Results and Discussion}

Selection of the input variables is very important for satisfactory forecasting models. Cross-correlations between lag input variables and output variables as well as the autocorrelation coefficient of the output variables were employed to determine the potential input variables. The correlation coefficients related to the four output variables are shown in Table 1.

According Table 1, weekly average minimum and maximum temperature of previous week and present week, weekly average morning and evening relative humidity of previous week and present week, weekly average sun shine hours of previous week and present week and weekly average pan evaporation of previous week and present week are significantly correlated with current week's average morning soil temperature at depth $5 \mathrm{~cm}$. All of these variables, except weekly average sun shine hours of previous week and present week, are significantly correlated with the current week's average morning soil temperature at depth $10 \mathrm{~cm}$.

Weekly average minimum and maximum temperature of previous week and present week, weekly average morning and evening relative humidity of previous week and present week, weekly average wind velocity of previous week and present week, weekly average sunshine hours of previous week and present week, and weekly average pan evaporation of previous week and present week are significantly related with current week's average evening soil temperature at depth $5 \mathrm{~cm}$. All these variables, except weekly average wind velocity of previous week and present week, are significantly correlated with current week's average evening soil temperature at depth $10 \mathrm{~cm}$. 
Table 1: Cross correlation coefficient between input and output variables for four models

\begin{tabular}{|c|c|c|c|}
\hline \multicolumn{2}{|c|}{ Soil-5cm at morning } & \multicolumn{2}{|l|}{ Soil-5cm evening } \\
\hline Past Min: Temp & 0.898 & Present Min: Temp & 0.687 \\
\hline Present Min: Temp & 0.505 & Past Min:Temp & 0.132 \\
\hline Past Max: Temp & 0.863 & Present Max: Temp & 0.982 \\
\hline Present Max: Temp & 0.506 & Past Max:Temp & 0.479 \\
\hline Present Rh Morning & -0.685 & Present Rh Morning & -0.698 \\
\hline Past Rh Morning & -0.228 & Past Rh Morning & -0.155 \\
\hline Past Rh evening & -0.713 & Present Rh evening & -0.92 \\
\hline Present Rh evening & -0.209 & Past Rh evening & -0.47 \\
\hline Present wind velocity & 0.065 & Present wind velocity & -0.714 \\
\hline Past wind velocity & 0.033 & Past wind velocity & -0.188 \\
\hline Past sun shine hours & 0.717 & Present sun shine hours & 0.856 \\
\hline Present sun shine hours & 0.175 & Past sun shine hours & 0.361 \\
\hline Present rainfall & 0.062 & Present rainfall & -0.068 \\
\hline Past rainfall & 0.027 & Past rainfall & -0.068 \\
\hline Past pan evaporation & 0.762 & Present pan evaporation & 0.786 \\
\hline Present Pan evaporation & 0.298 & Past pan evaporation & 0.336 \\
\hline \multicolumn{2}{|c|}{ Soil-10cm at morning } & \multicolumn{2}{|l|}{ Soil-10cm at evening } \\
\hline Past Min: Temp & 0.884 & Present Min: Temp & 0.745 \\
\hline Present Min:Temp & 0.485 & Past Min:Temp & 0.172 \\
\hline Past Max: Temp & 0.861 & Present Max: Temp & 0.922 \\
\hline Present Max: Temp & 0.502 & Past Max:Temp & 0.522 \\
\hline Present Rh Morning & -0.646 & Present Rh Morning & -0.732 \\
\hline Past Rh Morning & -0.223 & Past Rh Morning & -0.183 \\
\hline Past Rh evening & -0.74 & Present Rh evening & -0.913 \\
\hline Present Rh evening & -0.232 & Past Rh evening & -0.479 \\
\hline Present wind velocity & 0.057 & Present wind velocity & -0.198 \\
\hline Past wind velocity & 0.03 & Past wind velocity & -0.172 \\
\hline Present sun shine hours & 0.133 & Present sun shine hours & 0.858 \\
\hline Past sun shine hours & 0.203 & Past sun shine hours & 0.374 \\
\hline Present rainfall & 0.049 & Present rainfall & -0.058 \\
\hline Past rainfall & 0.016 & Past rainfall & -0.057 \\
\hline Past pan evaporation & 0.77 & Present pan evaporation & 0.814 \\
\hline Present pan evaporation & 0.319 & Past pan evaporation & 0.364 \\
\hline
\end{tabular}

As the autocorrelation coefficient at lag one of average morning soil temperature at depth $5 \mathrm{~cm}$ is highly significant, previous week's average morning soil temperature at the same depth was considered as an input variable when building 
the respective forecasting models. Similarly, the autocorrelation coefficients at lag one of the average morning soil temperature at depth $10 \mathrm{~cm}$ as well as those of average evening soil temperature at two depths suggested considering their own previous week's value as a potential input variable.

Based on MSE and $\mathrm{R}^{2}$ of the model of predicted values on actual values of soil temperature data, better FNN models and better NARX models which forecast morning and evening soil temperatures at two depths were selected. A summary of these eight models are given in Table 2 and Table 3.

Among the models considered, FNN and NARX models with architectures 6-81, 7-8-1, 5-8-1 and 6-7-1 were identified as the best models to forecast soil temperature at $5 \mathrm{~cm}$ and $10 \mathrm{~cm}$ depths in morning and in evening, respectively.

As shown in Table 2 and Table 3, best set of input variables for the model to forecast average morning soil temperature of present week at depth of $5 \mathrm{~cm}$ were average minimum and average maximum temperature, average pan evaporation, average relative humidity in the evening, average sun shine hours of previous week and average relative humidity in the morning of present week. All of the above mentioned variables other than sun shine hours were found to the best set of input variables for the model to forecast average morning soil temperature of present week at depth of $10 \mathrm{~cm}$. All of the above mentioned variables pertaining to the current week were in the best set of input variables for the models forecasting average evening temperature of present week at depth of $10 \mathrm{~cm}$.

In addition to the above mentioned variables and wind velocity of present week were found to be the best set of input variables to forecast average evening temperature of present week at depth of $5 \mathrm{~cm}$. The best sets of input variables for the four NARX models were as same as those of the respective FNN models. Input variables to the forecasting models depend on the depths as well as the time of the day.

In the NARX networks model, the soil temperature data at two different depths depends not only on the metrological data of the current week, but also on the soil temperatures data at depths of $5 \mathrm{~cm}$ and $10 \mathrm{~cm}$ in the previous week.

The weights $\left(w_{i j}, w_{j k}\right)$ and bias $\left(b_{j}, b_{k}\right)$ of the FNN and NARX models are shown in Table 4 and Table 5 (see Apendix) respectively.

The estimated soil temperatures for the morning and evening at two different depths were calculated to substitute weights and bias in (5). The FNN model for morning soil temperature at $5 \mathrm{~cm}$ is enumerated as an example in (8) 
Table 2: Model 1(a), 1(b) and Model 2(a), 2(b) - Soil temperature models in morning and evening at depth of $5 \mathrm{~cm}$ in FNN and NARX

\begin{tabular}{|c|c|c|c|c|}
\hline & \multicolumn{2}{|c|}{ Soil $-5 \mathrm{~cm}$ at morning } & \multicolumn{2}{|c|}{ Soil $-5 \mathrm{~cm}$ at evening } \\
\hline & $\begin{array}{c}\text { FNN } \\
\text { (model l (a)) }\end{array}$ & $\begin{array}{c}\text { NARX } \\
(\operatorname{model} 1(b))\end{array}$ & $\begin{array}{c}\text { FNN } \\
(\text { model } 2 \text { (a)) }\end{array}$ & $\begin{array}{c}\text { NARX } \\
(\text { model } 2(b))\end{array}$ \\
\hline $\begin{array}{l}\text { Input Layer } \\
\text { Nodes }\end{array}$ & \multicolumn{2}{|c|}{$\begin{array}{l}\text { (minimum and maximum temperature, } \\
\text { pan evaporation, sun shine hours, } \\
\text { Relative humidity at evening) of } \\
\text { previous week and Relative humidity at } \\
\text { morning of present week }\end{array}$} & \multicolumn{2}{|c|}{$\begin{array}{l}\text { (maximum temperature, Relative } \\
\text { humidity at evening, sun shine hours, } \\
\text { pan evaporation, wind velocity, Relative } \\
\text { humidity at morning minimum } \\
\text { temperature) of present week }\end{array}$} \\
\hline Hidden Layer & \multicolumn{2}{|c|}{ Nodes 8} & \multicolumn{2}{|c|}{ Nodes 8} \\
\hline Output Layer & \multicolumn{2}{|c|}{$\begin{array}{c}\text { Nodes } 1 \\
\text { (soil Temperature at morning) }\end{array}$} & \multicolumn{2}{|c|}{$\begin{array}{c}\text { Nodes } 1 \\
\text { (soil Temperature at evening) }\end{array}$} \\
\hline $\begin{array}{l}\text { MSE( for test } \\
\text { cases) }\end{array}$ & 0.410539 & 0.380263 & 1.03627 & 0.842445 \\
\hline $\mathrm{R}^{2}$ & $78 \%$ & $80 \%$ & $70 \%$ & $74 \%$ \\
\hline Parameters & $\begin{array}{l}\text { Leaming Rate- } \\
0.01\end{array}$ & & $\begin{array}{c}\text { Learning Rate - } \\
0.001\end{array}$ & \\
\hline & $\begin{array}{l}\text { Momentum Factor } \\
-0.03\end{array}$ & & $\begin{array}{c}\text { Momentum Factor } \\
-0.03\end{array}$ & \\
\hline
\end{tabular}

Table 3: Model 3(a), 3(b) and Model 4(a), 4(b) - Soil temperature models in morning and evening at depth of $10 \mathrm{~cm}$ in FNN and NARX

\begin{tabular}{|c|c|c|c|c|}
\hline & \multicolumn{2}{|c|}{ Soil $-10 \mathrm{~cm}$ at morning } & \multicolumn{2}{|c|}{ Soil $-10 \mathrm{~cm}$ at evening } \\
\hline & $\begin{array}{c}\text { FNN } \\
\text { (model 3 (a)) }\end{array}$ & $\begin{array}{c}\text { NARX } \\
(\operatorname{model} 3(b))\end{array}$ & $\begin{array}{c}\text { FNN } \\
\text { (model } 4 \text { (a)) }\end{array}$ & $\begin{array}{c}\text { NARX } \\
\text { (model } 4 \text { (b)) }\end{array}$ \\
\hline $\begin{array}{l}\text { Input Layer } \\
\text { Nodes }\end{array}$ & \multicolumn{2}{|c|}{$\begin{array}{l}5 \\
\text { (minimum and maximum temperature, } \\
\text { pan evaporation, Relative humidity at } \\
\text { evening) of previous week and Relative } \\
\text { humidity at moming of present week }\end{array}$} & \multicolumn{2}{|c|}{$\begin{array}{l}\text { (maximum temperature, Relative } \\
\text { humidity at evening, sun shine hours, } \\
\text {,pan evaporation, minimum temperature, } \\
\text { Relative humidity at morning) of present } \\
\text { week }\end{array}$} \\
\hline Hidden Layer & \multicolumn{2}{|c|}{ Nodes 8} & \multicolumn{2}{|c|}{ Nodes 7} \\
\hline Output Layer & \multicolumn{2}{|c|}{$\begin{array}{c}\text { Nodes } 1 \\
\text { (soil Temperature at moming) }\end{array}$} & \multicolumn{2}{|c|}{$\begin{array}{c}\text { Nodes } 1 \\
\text { (soil Temperature at evening) }\end{array}$} \\
\hline $\begin{array}{l}\text { MSE ( for test } \\
\text { cases) }\end{array}$ & 0.491188 & 0.44978 & 0.72719 & 0.639467 \\
\hline $\mathrm{R}^{2}$ & $80 \%$ & $80 \%$ & $70 \%$ & $74 \%$ \\
\hline \multirow[t]{2}{*}{ Parameters } & $\begin{array}{c}\text { Leaming Rate - } \\
0.01\end{array}$ & & Learning Rate -0.01 & \\
\hline & $\begin{array}{c}\text { Momentum Factor } \\
-0.03\end{array}$ & & $\begin{array}{c}\text { Momentum Factor } \\
-0.03\end{array}$ & \\
\hline
\end{tabular}




$$
O_{p k}=0.046901\left(\frac{1}{1+e^{25.0878 l_{1}-2.0921}}\right)+0.22131\left(\frac{1}{1+e^{-6.5069 l_{2}-0.52688}}\right)+\ldots-0.74431
$$

where $l_{1}, l_{2}, \ldots, l_{8}$ are the output of the $1^{\text {st }}$ neuron of the input layer.

Scatter plots of measured soil temperature against predicted for the test data set are shown in Figure 03 and Figure 04 for the FNN models and Figure 05 and Figure 06 for the NARX models. These figures depict that FNN and NARX models predict soil temperature with reasonably high accuracy.

The predicted values are very similar to the actual values in all cases. As shown in Table 2 and Table 3, the mean-square errors for the four models of NARX are $0.380263,0.842445,0.44978$ and 0.639467 . The MSE corresponding to FNN are $0.410539,1.03627,0.491188$ and 0.72719 . Lower values of the MSE are better. The $\mathrm{R}^{2}$ values of predicted values on actual values for the four NARX models are $0.80,0.74,0.80$ and 0.74 . The corresponding coefficients for FNN models are $0.78,0.70,0.80$ and 0.70 . The results indicate the suitability of FNN and NARX models for prediction of soil temperature at morning and evening at different depths. Since NARX models result in lower MSE and higher $\mathrm{R}^{2}$, it can be proposed that NARX models perform better than their FNN counterparts in forecasting morning and evening soil temperature at different depths.

Furthermore, NARX model is faster than the FNN model with respect to time taken for training, validation and testing. The comparisons of Central Processing unit Time (CPU) between four models for all cases are shown in Table 6 in Appendix.

Table 6: Central Processing unit Time between four models for all cases

\begin{tabular}{|c|l|l|}
\hline \multirow{2}{*}{ Model } & \multicolumn{2}{|c|}{ CPU time } \\
\cline { 2 - 3 } & \multicolumn{1}{|c|}{ FNN } & \multicolumn{1}{c|}{ NARX } \\
\hline Soil -5cm at morning & $1.17 * 10^{-4}$ seconds & $1.04 * 10^{-4}$ seconds \\
\hline Soil -5cm at evening & $1.11 * 10^{-4}$ seconds & $1.05 * 10^{-4}$ seconds \\
\hline Soil -10cm at morning & $1.18 * 10^{-4}$ seconds & $1.06 * 10^{-4}$ seconds \\
\hline Soil -10cm at evening & $1.12 * 10^{-4}$ seconds & $1.04 * 10^{-4}$ seconds \\
\hline
\end{tabular}

The results represent the CPU time of FNN and NARX models for selection of fastest models for forecasting soil temperature in the morning and evening at different depths. NARX models incurred lower CPU times. Finally, it can be inferred that NARX models are more efficient than FNN models. 


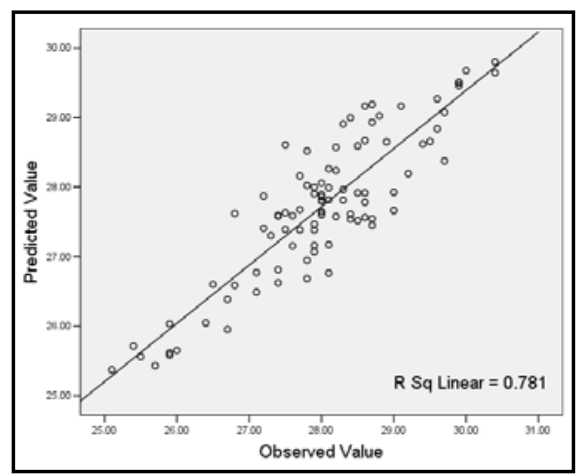

(a)

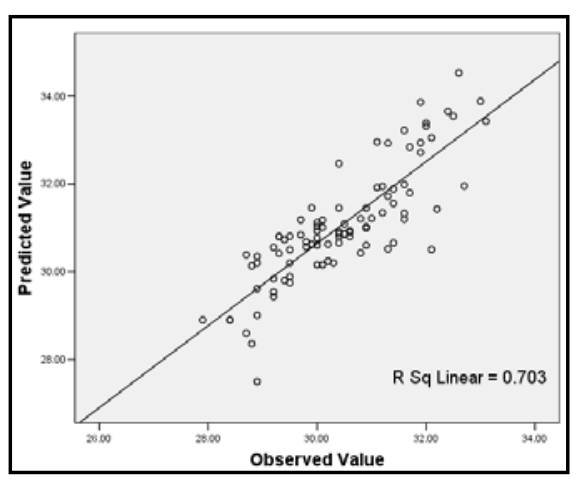

(b)

Figure 03: Comparison between exact and predicted soil temperature values at (a) morning and (b) evening in $5 \mathrm{~cm}$ for 2009-2010 of FNN

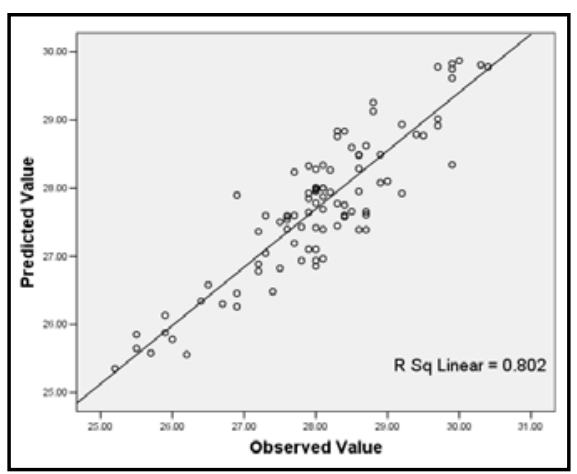

(c)

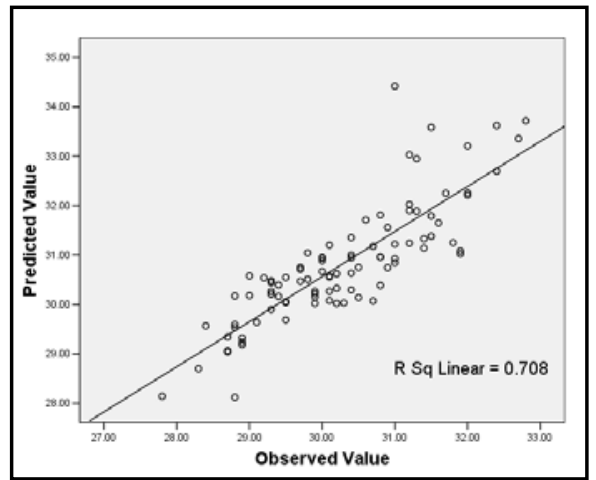

(d)

Figure 04: Comparison between exact and predicted soil temperature values at (c) morning and (d) evening in $10 \mathrm{~cm}$ for 2009-2010 of FNN

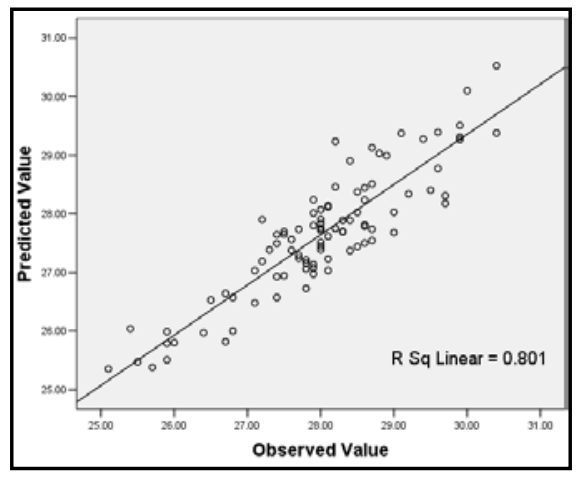

(e)

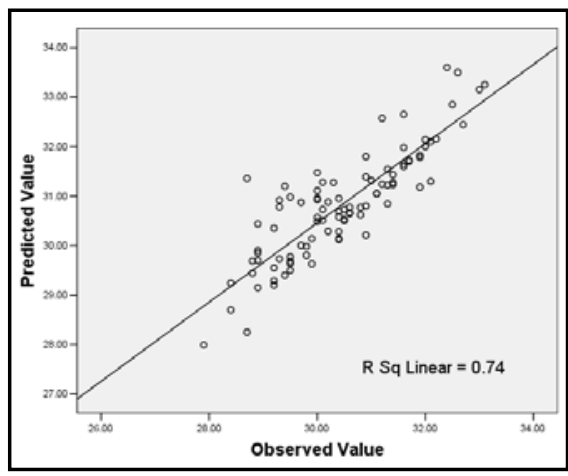

(f)

Figure 05: Comparison between exact and predicted soil temperature values at (e) morning and (f) evening in $5 \mathrm{~cm}$ for 2009-2010 of NARX 


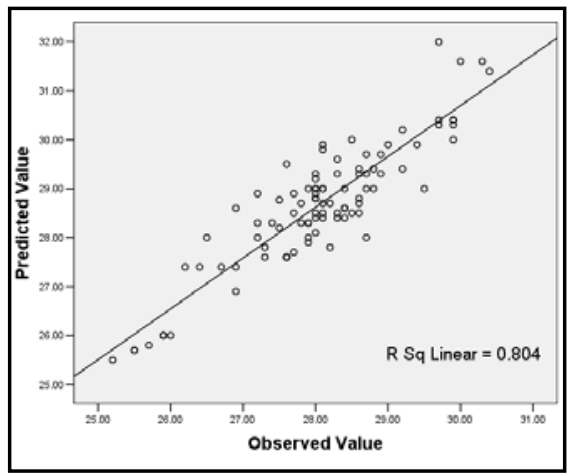

(g)

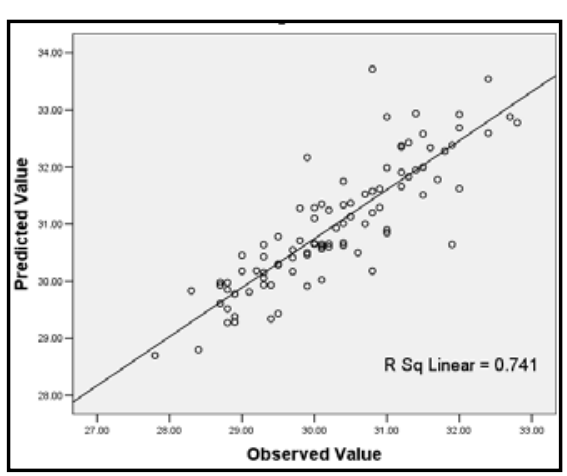

(h)

Figure 06: Comparison between exact and predicted soil temperature values at (g) morning and (h) evening in $5 \mathrm{~cm}$ for 2009-2010 of NARX

\section{Conclusions and Further Research}

The results exemplify that FNN and NARX based models produce reasonably high prediction accuracy for forecasting morning and evening soil temperature at depths $5 \mathrm{~cm}$ and $10 \mathrm{~cm}$ at the Bathalagoda area. Results also indicate that soil temperature can be written as a non linear function of the selected weather variables. Comparison of results from the two ANN models reveals that the NARX model is the better model to forecast morning and evening soil temperature at two depths at Bathalagoda area. However, researches can choose the model to predict the morning and evening soil temperatures at two different depths according to their requirements.

Minimum and maximum temperature, pan evaporation, relative humidity in the morning and evening during the previous week and present week were found to affect morning and evening soil temperature models at depths of $5 \mathrm{~cm}$ and $10 \mathrm{~cm}$ at the study area. Sun shine hours during the previous week and present week were found to affect the soil temperature both in the morning and evening at $5 \mathrm{~cm}$ depth. However, the effect of sunshine hours during current week at depth of $10 \mathrm{~cm}$ was found only in the evening. Wind velocity during current week was affected soil temperature at depth $5 \mathrm{~cm}$ only in the evening.

Further research needs to be carried out in order to generalize the findings from this study. Similar studies can be carried out on weekly data collected from different geographical areas. Data collected on a daily basis would be more appropriate and more accurate in developing forecasting model(s) for morning and evening soil temperature at different depths. 


\section{Acknowledgement}

The authors wish to express their sincere thanks to Rice Research and Development Institute (RRDI) for providing the meteorological data. Deep appreciation goes to the National Resources Management Center (NRMC) at Peradeniya for providing computerized data.

\section{References}

1. Amani, P., M. Kihl and A. Robertsson (2011). Multi-step ahead time prediction for single server queuing systems.Preoceedings of the 16th IEEE symposium of computers and communications.

2. Chun-Chieh, Y., O. P. Shiv and R. M. Guy (1997). An artificial neural network to estimate soil temperature.Canadian Journal of Soil Science.Pg 421-429.

3. Demuth, H., M. Beale and M. Hagan (2006). Neural Network Toolbox User's Guide, The Math Works Inc.

4. Droulia, F., S .Lykoudis, I. Tsiros, N .Alvertos, E. Akylas and I .Garofalakis (2009). Ground temperature estimations using simplified analytical and semi-empirical approaches.Solar Energy.volume 83,Pg 211-219.

5. Enrique, G., I. Braud, T .Jean-Louis, V. Michel, B. Pierre and C. JeanChristophe (1999). Modelling heat and water exchanges of fallow land covered with plant-residue mulch. Agriculture and Forest Meteorology.volume 97, Pg 151-169.

6. Felker, P., and H. Han (1997). Estimation of daily soil water evaporation using an artificial neural network.Journal of Arid Environments.Pg 251-260.

7. Gao, Z., L. Bian, Y. Hu, L .Wang and J .Fan (2007). Determination of soil temperature in an arid region.Journal of Arid Environments.volume 71, Pg 157-168.

8. Gao, Z., R. Horton, L .Wang, H. Liu and J. Wen (2008). An improved force restore method for soil temperature prediction. European Journal of Soil Science.volume 59, Pg 972-981.

9. George, R.K (2001). Prediction of soil temperature by using artificial neural networks algorithms.Nonlinear Analysis.volume 7,Pg 1737-1738.

10. Hayati, M., and Z. Mohebi (2008). Application of Artificial Neural Networks for Temperature Forecasting. International Journal of Engineering and Applied Sciences.volume 4, Pg 164-168. 
11. Haykin, S. (1999). Neural Networks: A comprehensive Foundation.(2nd ed.).Pg 156-169.Prentice Hall New Jersey, USA.

12. Kang, S., S .Kim, S .Oh and D. Lee (2000). Predicting spatial and temporal patterns of soil temperature based on topography, surface cover and air temperature. Forest Ecology and Management .volume 136, Pg 173-178.

13. Koçak, K., L .Şaylan and J. Eitzinger (2006). Nonlinear prediction of near surface temperature via univariate and multivariate time series embedding.Ecological Modelling.volume 173, Pg1-7.

14. Maria, P.J., J. Menezes, A. Guilherme and Barreto (2006). A new look at nonlinear time series prediction with NARX recurrent neural network. AIX Brazilian Neural Networks Symposium.Pg 23-27.

15. Mehmet, B (2010). The use of artificial neural networks for forecasting the monthly mean soil temperatures in Adana Turkey.Turkish Journal of Agriculture and Forestry.volume 35, Pg 83-93.

16. Mihalakakou, G (2002). On estimating soil surface temperature profiles.Energy and Buildings.volume 3,Pg 251-259.

17. Prangnell, J., G. McGowan (2009). Soil temperature calculation for burial site analysis.Forensic Science International.volume 191,Pg 10 -109.

18. Shahlla, A. A., and N.A. Omaima (2011). Backpropagation Neural Network Algorithm for Forecasting Soil Temperatures Considering Many Aspects: A Comparison of Different Approaches.The 5th International Conference on Information Technolog,Pg 43-51.

19. Tenge, A.J., F.B.S. Kagihura, R .Lal and B.R. Singh (1998). Diurnal soil temperature fluctuations for different erosion classes of an oxisol at Mlingano.Tanzania. Soil and Tillage Research.volume 9, Pg 211-217.

20. Tilakaratne, C.D (2004). A Neural Network approach for Predicting the Direction of the Australian Stock Market Index. MIT thesis .University of Ballarat. Australia.

21. Yang, C.C., S. O. Prasher, and G. R. Mehuys (1997). An Artificial Neural Network to Estimate Soil Temperature.Canadian Journal of Soil Science.volume 77, Pg 421-429.

22. Y1lmaz. T., A .Ozbek, A .Y1lmaz and O. Büyükalaca (2009). Influence of upper layer properties on the ground temperature distribution. Journal of Thermal Science and Technology.volume 29, Pg 3-51. 
Appendix

Table 4: Final values of weights and bias between input and hidden layer and hidden and output layer for Soil temperature models in morning and evening at depths of $5 \mathrm{~cm}$ and $10 \mathrm{~cm}$ in FNN

Soil -5cm at morning
\begin{tabular}{|c|c|c|c|c|c|c|c|c|}
\hline w11 & w21 & w31 & $\mathbf{w 4 1}$ & w51 & $\mathbf{w 6 1}$ & $\mathbf{w 1 1}$ & b1 & b1 \\
\hline-25.0878 & 24.068 & -4.6816 & -4.58 & -2.1658 & 0.68643 & 0.046901 & -2.0921 & -0.74431 \\
6.5069 & -5.1561 & -3.493 & 0.72022 & 4.2215 & 0.15748 & 0.22131 & -0.52688 & \\
3.5842 & -1.5485 & 0.57732 & -0.52192 & 0.57099 & -1.235 & 0.63651 & 0.31434 & \\
0.9116 & -0.45455 & 0.08829 & -1.6507 & 2.7837 & -3.4263 & -0.18475 & 0.73836 & \\
3.1439 & 10.4517 & -4.332 & -4.0799 & 4.361 & -5.9658 & 0.051342 & -0.67883 & \\
-0.85952 & 9.8097 & 0.26394 & 0.17261 & -1.7793 & 1.3155 & 0.67357 & -2.9826 & \\
1.0162 & 10.6334 & -9.0947 & 0.94402 & -2.7839 & 4.3155 & -0.01467 & -3.4155 & \\
9.1176 & 2.7558 & -5.3531 & -5.7284 & 3.641 & 2.7089 & -0.05856 & 4.2046 & \\
\hline
\end{tabular}

Soil $-5 \mathrm{~cm}$ at evening

\begin{tabular}{|c|c|c|c|c|c|c|c|c|c|}
\hline w12 & w22 & w32 & $\mathbf{w 4 2}$ & $\mathbf{w 5 2}$ & $\mathbf{w 6 2}$ & $\mathbf{w 7 2}$ & $\mathbf{w 2 1}$ & $\mathbf{b 2}$ & b1 \\
\hline 3.8128 & -2.7119 & -2.2454 & -8.5821 & 2.04 & 1.8105 & -1.1375 & 0.044141 & -3.8443 & -0.05764 \\
-10.7586 & -13.4685 & -15.1252 & 14.1343 & -4.3494 & -0.27792 & -7.6523 & 0.023435 & 4.0344 & \\
8.5688 & -0.21005 & 0.1758 & -1.5368 & 0.40123 & 0.87973 & 0.3263 & 0.84445 & -3.7644 & \\
-56.2649 & -25.2343 & 5.9352 & 20.9217 & 1.6373 & -7.6184 & 15.3425 & 0.036461 & 14.2825 & \\
11.0854 & -34.3693 & -25.767 & 2.4772 & -9.1259 & -7.5005 & 13.6556 & -0.20977 & 5.8496 & \\
-422.7958 & -61.8657 & -36.5527 & -6.587 & -74.8849 & -78.525 & 55.3088 & -0.01506 & 42.013 \\
97.7683 & 124.964 & -47.2229 & 353.6807 & -55.3973 & 38.305 & -443.233 & -0.02801 & -63.9509 & \\
13.2605 & 8.1943 & 12.7421 & 13.0075 & 21.0812 & 21.4246 & -1.5851 & 0.064266 & 1.5612 & \\
\hline
\end{tabular}


Soil $-10 \mathrm{~cm}$ at morning

\begin{tabular}{|l|l|l|l|l|l|l|l|}
\hline \multicolumn{1}{|c|}{ w13 } & \multicolumn{1}{c|}{ w23 } & \multicolumn{1}{c|}{ w33 } & \multicolumn{1}{c|}{ w43 } & \multicolumn{1}{c|}{ w53 } & \multicolumn{1}{|c|}{ w31 } & \multicolumn{1}{c|}{ b3 } & \multicolumn{1}{c|}{ b1 } \\
\hline 6.1749 & -0.62305 & -3.7048 & 3.6582 & -2.1814 & -2.1649 & -7.631 & 0.49232 \\
2.26 & -10.9246 & -7.6758 & 3.4672 & -7.8289 & -0.07923 & 6.2552 & \\
1.9694 & -3.171 & -3.2688 & 2.6299 & -3.8761 & -0.2657 & -0.14572 & \\
-2.279 & 5.4931 & -4.537 & 5.8704 & -6.1368 & 0.077977 & -2.0507 & \\
3.4781 & -2.3283 & -0.57003 & 0.54505 & -1.357 & 0.80237 & 0.074373 & \\
-0.031317 & -1.5377 & -1.3841 & 8.7067 & -3.6753 & -0.09614 & 6.5864 & \\
9.4818 & -5.2916 & 0.1983 & 8.3636 & -7.2671 & -0.03405 & 2.8929 & \\
-0.6218 & -8.6949 & 1.3973 & -0.53404 & -0.67915 & -0.3416 & 3.3312 & \\
\hline
\end{tabular}

Soil $-10 \mathrm{~cm}$ at evening

\begin{tabular}{|l|l|l|l|l|l|l|l|l|}
\hline \multicolumn{1}{|c|}{ w14 } & \multicolumn{1}{|c|}{ w24 } & \multicolumn{1}{|c|}{ w34 } & w44 & w54 & \multicolumn{1}{|c|}{ w64 } & \multicolumn{1}{|c|}{ w41 } & \multicolumn{1}{|c|}{ b4 } & \multicolumn{1}{c|}{ b1 } \\
\hline-11.8211 & -0.37325 & 1.63 & 0.89571 & 2.3828 & -0.26794 & -0.34577 & 3.0662 & -0.05787 \\
-2.0752 & 6.3728 & 3.9961 & -2.2987 & 4.8589 & 1.9855 & 0.23676 & -2.3907 & \\
0.63216 & -5.1102 & -2.1873 & -0.8865 & -4.9385 & 2.7379 & 0.16691 & -0.29203 & \\
1.1042 & 1.0492 & -0.48202 & -1.5482 & -1.4466 & 0.65979 & -0.65259 & -1.3593 & \\
1.8672 & 4.8832 & 1.9242 & 1.137 & -0.84237 & 15.0754 & -0.03749 & 0.27468 & \\
3.4021 & -0.3687 & -1.6138 & -1.7712 & -3.9036 & -11.8627 & 0.0921 & 4.0568 & \\
6.4211 & 0.08737 & 0.10734 & -1.1579 & 2.8145 & 1.1008 & 0.48869 & -3.6899 & \\
\hline
\end{tabular}


Table 5: Final values of weights and bias between input and hidden layer and hidden and output layer for Soil temperature models in morning and evening at depths of $5 \mathrm{~cm}$ and $10 \mathrm{~cm}$ in NARX

Soil-5cm at morning

\begin{tabular}{|c|c|c|c|c|c|c|c|c|c|c|c|c|c|c|}
\hline \multicolumn{10}{|c|}{ (Weight to layer 1 from input 1) } & \multicolumn{1}{|c|}{ Weight to layer } & \multicolumn{2}{c|}{ Bias } \\
\hline w11 & w12 & w13 & w14 & w15 & w16 & w17 & w18 & w19 & W110 & w21 & w22 & w23 & b1 & b2 \\
\hline 1.3419 & 0.3737 & -1.0889 & -1.1913 & 0.14391 & -1.2187 & -0.2942 & 1.2736 & -0.4216 & -1.084 & -0.7233 & -0.6585 & 1.2412 & -3.3298 & -0.9484 \\
0.9747 & 0.3926 & -1.476 & -1.2733 & 0.81363 & -0.3886 & -0.8861 & -0.5268 & 1.585 & 1.1881 & -0.1245 & 0.61499 & 0.055058 & -2.3784 & \\
-0.42396 & -1.188 & 0.34606 & 0.50498 & 0.912174 & -0.0248 & -1.1909 & -1.2396 & 0.95416 & 1.1665 & 0.75057 & 1.1675 & 1.2967 & 1.427 & \\
0.00866 & 0.4978 & 0.90498 & -1.2777 & -0.48463 & 1.2463 & -1.9139 & 0.51131 & 0.96288 & -0.755 & 0.40862 & 0.3205 & -1.0364 & -0.4756 \\
-0.93374 & 0.170 & -0.8584 & -1.0021 & -1.3887 & -0.0002 & 1.6304 & 0.21214 & -1.0875 & -0.117 & -0.0059 & -0.8953 & 0.110295 & 0.47568 \\
0.026368 & 0.9506 & -0.2084 & -1.3125 & -0.81269 & -0.0386 & -0.7887 & 1.0857 & -1.2943 & -1.327 & 0.21919 & 1.1445 & 1.0983 & 1.427 & \\
-1.2872 & 0.4358 & -0.4098 & 0.69376 & 0.67295 & -1.3079 & 1.3947 & -0.9126 & -0.8857 & -0.577 & -0.8443 & -1.3311 & -0.87155 & -2.3784 \\
-1.6832 & -0.865 & -1.5837 & 0.23133 & 0.64294 & 1.0894 & -0.6074 & 1.0904 & 0.13822 & -0.056 & -0.5171 & 0.4787 & 1.2386 & -3.3298 & \\
\hline
\end{tabular}

Soil-5cm at evening

\begin{tabular}{|c|c|c|c|c|c|c|c|c|c|c|c|c|c|c|c|c|c|c|}
\hline \multicolumn{14}{|c|}{ (Weight to layer 1 from input 1 ) } & \multicolumn{3}{|c|}{ Weight to layer } & \multicolumn{2}{|c|}{ Bias } \\
\hline w11 & w12 & w13 & w14 & 15 & w16 & 17 & 18 & 19 & 110 & w111 & w112 & w113 & w114 & 21 & w22 & w23 & b1 & b2 \\
\hline-0.057 & -0.816 & 133 & 0.248 & 0.6325 & 1.0461 & -1.113 & -0.255 & 0.555 & 0.9448 & -0.797 & 0.4949 & 1.1118 & 1.1101 & 0.5934 & -0.13 & -0.888 & 3.189 & 0.5283 \\
\hline 0.4465 & -1.235 & -0.93 & 1.056 & 1.0965 & -0.778 & 0.1696 & 0.3346 & 0.881 & -0.138 & -0.404 & 0.454 & -1.056 & 1.2137 & 0.0593 & 0.119 & 0.8646 & -2.27 & \\
\hline 0.6442 & -1.092 & -0.77 & -0.85 & 0.0411 & 0.5697 & 0.8792 & 1.0474 & 0.408 & 1.1 & -0.995 & 0.7471 & 0.0187 & 0.9753 & 0.5093 & 0.09 & 1.0754 & -1.36 & \\
\hline-0.822 & -0.805 & $|-0.89|$ & -0.56 & 0.9142 & 0.0526 & -0.883 & 0.8714 & $|-0.45|$ & -1.237 & -0.148 & -0.642 & 0.678 & 33 & 0.0071 & 0.759 & -0.713 & 0.456 & \\
\hline 1.1563 & 0.0694 & -1.05 & -1.1 & -0.68 & 0.6516 & -0.187 & 0.7852 & -1.16 & 0.9006 & -0.148 & 0.6746 & -0.977 & 0.4836 & 0.8141 & 0.254 & 1.0341 & 0.456 & \\
\hline 0.0959 & -0.963 & 0.597 & -0.97 & -0.196 & 1.0415 & -0.473 & 1.2445 & $\mid-1.03$ & 0.0781 & -0.474 & -0.245 & -1.275 & 0.5537 & -0.753 & 1.222 & 0.4823 & 1.367 & \\
\hline 1.0921 & -1.125 & -0.14 & -1.14 & -0.347 & -0.692 & & -0.835 & $|-0.57|$ & 1.2527 & 1.0918 & -1.171 & -0.155 & & 0.7045 & 0.346 & 3 & 2.278 & \\
\hline 0.3939 & 0.1483 & 0.027 & -0.85 & 0.5301 & 1.189 & 0.8842 & 0.4609 & 0.915 & 1.0201 & -0.015 & 1.0023 & -1.001 & -1.179 & -0.65 & 1.02 & 0.5024 & 3.189 & \\
\hline
\end{tabular}




\section{Soil-10cm at evening}

\begin{tabular}{|c|c|c|c|c|c|c|c|c|c|c|c|c|c|c|c|c|}
\hline \multicolumn{12}{|c|}{ (Weight to layer 1 from input 1) } & \multicolumn{3}{|c|}{ Weight to layer } & \multicolumn{2}{|c|}{ Bias } \\
\hline w11 & 12 & w13 & 14 & w15 & w16 & w17 & w18 & w19 & w110 & 111 & w112 & w21 & w22 & w23 & b1 & b2 \\
\hline-1.100 & 704 & . & & & & & & & & & & & & & & -0.6 \\
\hline-1.359 & 0.0824 & 0.662 & 0.509 & -1.315 & & 1.2032 & 0.2709 & & & & & -0.725 & & & 2.145 & \\
\hline 0.3478 & 0.8873 & -0.84 & -1.21 & | 0000 & & & & & & & & 0.4174 & & & -1.07 & \\
\hline-0.819 & 0.7761 & -1.23 & 1.106 & 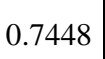 & 1.1223 & 1.3983 & & & & & & -0.917 & & 0.116 & 0 & \\
\hline 0.7517 & -0.376 & -1.21 & -0.1 & 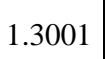 & -0.114 & -0.822 & -1.049 & & & & & -0.127 & & & 1.073 & \\
\hline 0.7683 & -0.232 & -0.86 & 0.126 & -1.756 & 0.3811 & -0.478 & -1.171 & -0.28 & 1.549 & -0.92 & 0.379 & 0.3607 & -0.724 & 0.3541 & 2.145 & \\
\hline-0.24 & 1.2497 & -0.89 & -1.08 & -1.119 & -0.476 & 0.5474 & 0.2129 & 0.619 & 1.1766 & 0.6625 & 0.5482 & 0.1035 & 0.9173 & -1.266 & -3.22 & \\
\hline
\end{tabular}


